\title{
Public Transport Route Network Optimization Criteria’s for Cities
}

\author{
Rasa Ušpalytè-Vitkūnienė (iD ${ }^{*}$, Justina Kolodinskaja ${ }^{2}$ \\ ${ }^{1}$ Road Department, Vilnius Gediminas Technical University, Vilnius, Lithuania \\ ${ }^{2}$ Vilnius District Municipality, Vilnius, Lithuania
}

Received 04 February 2020; accepted 31 March 2020

\begin{abstract}
The city's approach to transport management is defined by the City Master Plan and City Strategic Plan and Vilnius Sustainable Urban Mobility Plan (Vilnius Sustainable Mobility Plan - SUMP, 2018), which have identified scenarios for the transportation system till 2030. A SUMP fosters a balanced development of all relevant transport modes, while encouraging a shift towards more sustainable modes. Its key objective is to design a modern, efficient, fast, comfortable and safe public transport system, comparable to those of EU capital cities. Vilnius aims to maintain an environmentally friendly public transport fleet that represents the biggest share in the city's modal split. Still there is a problem with matching the public transport network with the fast changing urban situation. Citizen's are moving from one part of the city to the other, that shows that is necessary to have tool helping to decide how and when to change public transport route. The aim of this research was to create the clear methodology for the public transport route network maintenance based on the main public transport route criteria's.
\end{abstract}

Keywords: public transport, route network, criterion analysis.

\section{Introduction}

Public transport is a service that many cities recognize as an important aspect of developing socially, environmentally and economically sustainable communities (Van Lierop et al., 2018). Public transport is recognised as a main component of a sustainable city. An attractive and reliable public transport service is an important element for creating sustainable mobility (European Commission..., 2007). Transfer from personal cars to public transport is one of the most important means of overcoming congestion, noise and emissions (carbon emissions) facing many urban areas (Mulley \& Nelson, 2009; Cats \& Jenelius, 2015; Cats et al., 2017).

A pan-European survey by the European Commission found that the Europeans believe that the two best ways to improve urban transport are lower Public transport (PT) prices (59\% of all respondents) and better public transport service (56\%). The case of Tallinn, Estonia from January 1 of 2013 performs a full scale experiment: provides a unique opportunity to explore the impacts of FFPT (free-fare public transport). In 2012 people said that they will visit more often shopping and leisure areas when public transport will become fare-free. This reason was one of the motivations for implementing FFPT. Almost a year after the implementation of FFPT, public transport usage increased by $14 \%$ and there is an evidence that the mobility of low-income residents has improved (Cats et al., 2017). Italian researchers have described two methods for replanning the public transport system to reduce the exploitation budget of the public transport system. The first defines a situation where public transport services exceed the needs of some parts of the network, and the second where the needs of passengers are not met (D'Acierno et al., 2014).

Public transport system offering a direct service between every destination would have low occupancies, low frequencies, high costs and high-energy use per passenger. The solution of the problem is public transport networks that are characterized by services on physical networks of roads. Increased numbers of jobs and rising residential populations is significant for creation public network route (Stone \& Mees, 2010; Cats \& Jenelius, 2015).

A transportation system consists of two elements: transport supply and travel demand. The public transport must be cater for passengers with very different needs, ranging from trip in peak period to all day access to shops and community centres. Travel demand is expressed by the number of users using the network with a specific mode, at a given time of day. The equilibrium between transport supply and travel demand produces a flow pattern on network links (Arampatzis et al., 2004; Stone \& Mees, 2010). Cities are trying to implement policies, which aims to increase demand for public transport use, to retain current users, to attract new users and to take into account passengers with special and low mobility needs choice. Passengers can be divided into public transport market segments based on their socio-economic, geographical attributes and travel patterns, including both users and non-users of the existing public

*Corresponding author. E-mail: rasa.uspalyte@vgtu.lt

\section{Copyright (C) 2020 The Author(s). Published by VGTU Press}

This is an Open Access article distributed under the terms of the Creative Commons Attribution License (http://creativecommons.org/licenses/by/4.0/), which permits unrestricted use, distribution, and reproduction in any medium, provided the original author and source are credited. 
transport services (Abenoza et al., 2017). Van Lierop et al. state that users will continue to use public transport and recommend it to others only when they are satisfied with the service performance. Some public transport users are not satisfied with the system but continue to use because do not have any alternative. The many people minds that the trains, trams and buses synonymous is discomfort and crowding, therefore very important that public transport users would feel comfortable and safe. The public transport vehicles must be clean, with sufficient free spaces, seating capacity and satisfactory temperature in vehicle. The personnel skills, frequency, reliability, punctuality, travel time, access time, network coverage, number of transfers, stop location, waiting time, information at stops, costs (types of tickets, ticket selling network) are just as important indicators of satisfaction of public transport service. The main reasons why public transport users may stop to using the system are changing the location of their home or job and dissatisfied with service (Van Lierop et al., 2018). Abenoza et al. have done the study in the field "how consumer satisfaction varies". The researching results show that women, the youngest and oldest groups of passengers are more satisfied with public transport than others. It is observed that citizen's are more ambitious and more travelling than those living in small and medium size counties (Abenoza et al., 2017).

The idea that public transport network is less flexible than travelling in personal cars has encourage to set up Demand-Responsive Transport (DRT). DRT provided service from door-to-door especially for restricted usage people, for example the disabled and elderly. Interested users could place their requests by phone some days before they want to travel and the operator would plan the service. The booking office is tasked with planning routes and ordering travel services to reflect requests made to the service, both phone and online booking has been adopted. This service is equally applicable to areas of low demand that exist within urban and suburban areas whether this is at the urban fringe or within areas where for socio-demographic reasons there is insufficient demand to make a conventional, fixed route. In the UK is a bus service which is permitted to carry passengers separate fares or it could be a service primarily designed for some other purpose, for example the delivery of post or school children service. Flexible transport issue is where demand and supply is often does not match. Another idea was suggested that personal transport services such as rental cars and taxis could supplement public transport system (Mulley \& Nelson, 2009; Shang et al., 2014; Cats \& Jenelius, 2015).

There are popular mobile applications such as route planning and recommendation that take benefit for public transport users. The developed internet and mobile applications help and offer to the user who wants to travel from one place to another the option of best route. The concept of an ideal route is determined by various criteria for planning and evaluating routes. According to a study, twenty out of eight-one Izmir people chose the shortest path as the main criterion for route selection in the survey. The Dijkstra's Algorithm finds the shortest paths from the source vertex to all other vertices in a short time but it doesn't take the number of transfers or the walking distances that is important for end-users. For this reason the algorithm was modified. Modified Dijkstra's Algorithm based on minimizing number of transfers and walking distance by slightly increasing distance of the path. A Modified Dijkstra's Algorithm is tested in the Izmir (Turkey) public transport network which it consists of bus, metro, ferry and light railway. Jian-lin explained that considering the number of transfers and walking distances, the results of the modified method are significantly better than of the Dijkstra's Algorithm (Shang et al., 2014; Bozyiğit et al., 2017).

There are a number of criteria for the operation of the public transport route network. For the efficient operation of public transport in the city, some must be as large as possible, while others must be balanced between defined values. The tool, which support decisions for the public transport route network in the cities would, is very helpful for the operators. The aim of this research was to create the clear methodology for the public transport route network maintenance based on the main public transport route criteria's. Object of this research is an existing public transport route network, for the initiation of new lines should be use other methodology.

\section{Principles of creation and modifying a public transport network}

Transport network modelling assesses the four basic components of the travel pattern in a study area: trip generation, trip distribution, modal share, and traffic assignment. The main aim is to improve efficiency of the public transport and increase its competitiveness or to discourage the use of the private modes (Arampatzis et al., 2004). A network must be a simple, as well as be stable. The second very important idea is to provide a stable, consistent, high quality service all day, rather than operating in peak and off-peak periods, at weekends and nights (Stone \& Mees, 2010).

Public transport planning depends not only on service delivery and scheduling but also on a planning basis. Germany, Austria and Switzerland as well as North America have demonstrated that urban residents for more intensive use public transport when more attention is being paid for planning of public transport as a sustainable network with minimal number of transfers (Mees \& Dodson, 2011). The public transport planners have attempted to avoid transfers by designing routes that serve for the most popular roads and by creating circuitous bus routes that link many destinations, but the network approach includes transfers. The public transport based on effective transfer requires careful planning to ensure that the inconvenience would be as minimal as possible. Easy transferring requires attention to timetables and physical facilities. Accidental transfers are possible when all lines operate frequently, generally up to a limit of every 10 minutes (Stone \& Mees, 2010). 
Based on Australian cities experience there are several public transport networks planning. The first principle is to provide a simple and steady inter-connected network of public transport lines that structure and schedule are easy for users to learn and understand. The second principle of network planning is to accept that many of passengers will need to transfer between services to access their destination. This need is increasing in scattered cities, especially with a low or limited concentration of activity outside the city centre. It is very unlikely that the passenger will find their trip both beginning and ending on the same route. Therefore, one of the main tasks is to organize an easy transfer. Apply these two principles through five key practices:

- key practice 1: simple and direct network structures. Public transport networks should be organised on the principle of "one section - one line".

- key practice 2: plan a hierarchy of lines into a network. Network lines hierarchy differ in capacity and speed. The range of lines that create a simple network structure be divided into groups: high-speed high-capacity cross-town links; inter-suburban connecting links; local supplier services. Connecting lines together should create a simple network structure.

- key practice 3: plan for speed, consistency and reliability. Public transport planning should aim for travel speeds comparable to or faster than door-to-door travel times that can be achieved by car. This in practice requires intrusions to support priority for public transport vehicles (dedicated lanes and priority at intersections).

- key practice 4: coordinate comfortable transfers. The task is to provide a basic structure of lines operating at high frequency so that waiting times at stops on these lines are minimal and timetables are not required. Frequencies of six services per hour (every ten minutes) are the minimum necessary to avoid timetabled connections.

- key practice 5: provide clear, accessible and consistent information and marking. Very important that be included information about timetable frequencies as well as information about zones and fares. In the major stops public transport users must be able to buy a ticket (Mees \& Dodson, 2011). However, Abenoza et al. assert that an important goal is increase the knowledge of non-public transport users in terms of tickets, timetable, transfers and service characteristics, while the latter would focus on personal advantages attained from using public transport (Abenoza et al., 2017).

In addition to network planning principles, the institutional framework for operationalising such principles was also assessed. The international example of this institutional form was the "European Verkhersverbund" (EVV) model which is spread in Germany, Austria and Switzerland. In the cities where this model was started to develop, it has proved very successful (Mees \& Dodson, 2011).

The researchers Cats and Jenelius determine that one important principle modifying a public transport network is the increase of capacity on alternative lines such as increasing the frequency on existing lines, or running replacement lines for the disrupted line. The benefit of this strategy is that increasing capacity through increased line frequency means that the transfer and waiting times will decrease for passengers who are forced to choose alternative travel routes (Cats \& Jenelius, 2015).

Yet another approach to modifying public transport network is to provide separate services for different markets: express buses and trains for peak-period users; regular buses for local trips along busy corridors; car like "dial-a-bus" for low demand corridors and times. However, the problem is that the more public transport becomes better customized, the less it is superior in environmental and economic approach (Stone \& Mees, 2010).

\section{The main criteria of $P T$ routes}

According to Turas (2012) investigation on public transport development possibilities in Lithuania using intelligent transport systems, in order to be more popular, public transport should serve more frequently, be fast, reliable and convenient. These are the basic needs identified by PT passengers. Skietrys et al. (2008) also mentioned accessibility, reliability, willingness of the service provider to help, and retaining competence among the most important evaluation criteria.

A survey done by Beirão and Cabral (2007) people preferring cars for the following reasons: lower time consumption, overloaded PT vehicles, lack of comfort, uncertainty of time, lack of control, unreliability, long waiting time, flexibility shortage, and long walking time to the stop.

It is extremely important for passengers to spend as little time as possible on their journeys with the minimum number of connections available. The White Paper (European Union, 2001) mentions the characteristics of quality of service, i.e. frequency, convenience, accessibility, reliability and integration of different modes of transport, while access to information on journey times and route alternatives is equally important for ensuring seamless door-to-door passenger mobility. Moreover, the Green Paper mentions that urban infrastructure, which includes more than just roads, cycle lanes and so on. But also trains, buses, public spaces, parking lots, bus stops and stations must be of high quality. In addition, citizens want public transport to meet their needs for quality, efficiency and accessibility. 
After analyzing foreign literature and data collected by Lithuanian operators, the main indicators for evaluation and optimization of public transport routes were distinguished:

1. Number of trips on the route;

2. Relative number of passengers on the route;

3. Criteria for transport work;

4. Route utility criteria;

5. Route Loss Criteria;

6. Vehicle fill unevenness rate;

7. Fare rate.

\section{Number of trips on the route}

The number of trips on the route criteria defines the total number of weekday trips, which represents the number of passengers boarded on all route vehicles during the whole working day.

Skietrys et al. (2008) consider PT to be a modern means of transporting persons using vehicles capable of transporting a large number of people in the short term. Therefore, the greater the number of passengers carried, the more efficient the route. The authors also state that PT should serve all areas where PT is needed. Therefore, the low number of passengers does not mean that this route needs to be eliminated. It is possible to reduce the driving frequency of vehicles during certain hours.

\section{Relative number of passengers on the route}

The relative number of passengers on the route shows the relation to the occupancy of vehicles. This indicator shall be calculated by dividing the total number of daily journeys on working days by capacity of the public transport vehicles factor:

$$
R=\frac{N_{o}}{k},
$$

where: $R$ - relative number of passengers on the route; $N_{o}$ - total number of daily journeys on working day; $k$ - capacity of the public transport vehicles on the route.

\section{Criteria for transport work}

The transport work criterion represents the number of passengers per $1 \mathrm{~m}^{2}$ of free floor area of the vehicle (excluding seating area). This coefficient is calculated by dividing the number of passengers in the vehicle by the useful area of the vehicle:

$$
K_{1}=\frac{N}{A},
$$

where: $K_{1}$ - transport work coefficient; $N$ - number of passengers; $A$ - useful area of the vehicle.

\section{Route utility criteria}

The route utility criterion shows the average number of passengers travelling on the route, and at the same time the payback of the PT route and the benefits to the PT operator. If this number is low compared to other routes, the route is lightly loaded. The number of passengers per $1 \mathrm{~km}$ is calculated by dividing the number of passengers on the route by the length of the route:

$$
K_{2}=\frac{N}{L}
$$

where: $K_{2}$ - route utility coefficient; $N$ - number of passengers; $L$ - length of the route.

\section{Route Loss Criteria}

Route Loss coefficient shows a $1 \mathrm{~km}$ loss - calculated from the average cost of $1 \mathrm{~km}$ operating on the route minus revenue per $1 \mathrm{~km}$ of mileage. It shows how much the revenue does not cover the cost per $1 \mathrm{~km}$ (with minus sign - the revenue outweighs the cost, i.e. the route is profitable).

$$
R_{L}=C-R_{E},
$$

where: $R_{L}$ - route loss coefficient; $C$-average cost per $1 \mathrm{~km}$ of the route; $R_{E}$ - revenue per $1 \mathrm{~km}$.

\section{Vehicle fill unevenness ratio}

Vehicle fill unevenness ratio - indicates whether vehicle fills on a route are evenly distributed across the route, or whether certain sections of the vehicle run without passengers. This coefficient is calculated by dividing the amount of the minimum number of passengers on a particular route by the average number of passengers for a given segment: 


$$
K_{3}=\frac{\sum N_{\text {Min }}}{\sum N_{\text {Aver }}},
$$

where: $K_{3}$ - vehicle fill unevenness ratio; $N_{\text {Min }}$ - the minimum number of passengers on a particular route; $N_{\text {Aver }}-$ average number of passengers for a given segment.

\section{The Fare rate}

The fare rate - the cost factor for 1 passenger per $1 \mathrm{~km}$ shows whether the route is profitable or unprofitable, considering the average return on the passenger. This indicator is calculated as follows:

$$
K_{4}=\frac{M R_{L}}{N},
$$

where: $K_{4}$ - fare rate - the cost factor for 1 passenger per $1 \mathrm{~km} ; M$ - mileage on a particular route; $R_{L}$ - route loss coefficient; $N$-number of the passengers on the route.

\section{The methodology of PT route network maintenance}

Of the 6 public transport efficiency criteria, the number of journeys on a route, the relative number of passengers on the route, and the route loss criteria were rejected because they are included in the left criteria's expressions. The following four key indicators, which best and most accurately reflect the efficiency, economy and comfort of the public transport route, are highlighted and analysed below (Figure 1).

1. Number of trips on the route

2. Relative number of passengers on the route

3. Criteria for transport work

4. Route utility criteria

5. Route Loss Criteria

6. Vehicle fill unevenness rate

7. Fare rate
$\mathrm{X}$ (Reflected in all other criteria's)

$\mathrm{X}$ (reflected in the Criteria for transport work)

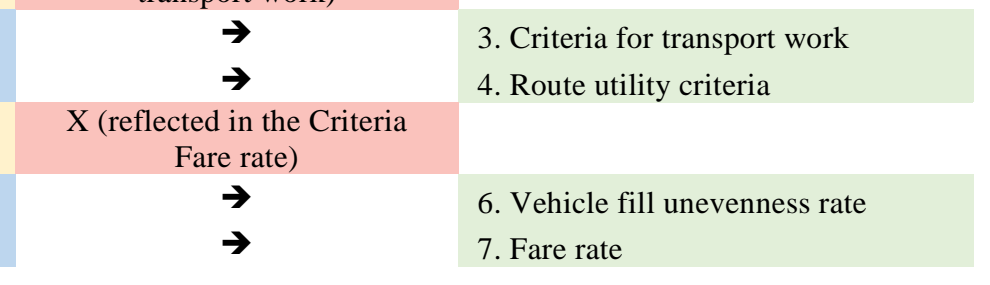

Figure 1. The highlighted main indicators for the PT route network maintenance

Based on the operator's operational experience and the needs and satisfaction rates of public transport passengers, coefficients have been established for the selected criteria (Table 1).

Table 1. Set coefficients rates for efficient public transport

\begin{tabular}{|c|c|c|c|}
\hline No. & Criteria & Aspiration & Effective operation rate \\
\hline$K_{1}$ & Criteria for transport work & $5 \mathrm{pass} / \mathrm{m}^{2}$ & 1 pass $/ \mathrm{m}^{2} \leq K_{1} \leq 7 \mathrm{pass} / \mathrm{m}^{2}$ \\
\hline$K_{2}$ & Route utility criteria & As max as possible & $K_{2} \leq 5.0$ \\
\hline$K_{3}$ & Vehicle fill unevenness ratio & 1.0 & $0.8 \leq K_{3} \leq 1.0$ \\
\hline$K_{4}$ & The fare rate & 0.00 & $K_{4} \geq-0.5$ \\
\hline
\end{tabular}

Everybody knows, that public transport must also be a social service that guarantees connectivity, combining passenger comfort and best-used capacity, the optimal number of passengers per $1 \mathrm{~m}^{2}$ of vehicle should be from $1 \mathrm{pass} / \mathrm{m}^{2}$ to 7 pass $/ \mathrm{m}^{2}$. With such indicators of public transport route, public transport performs optimal transport work and at the same time is comfortable for passengers. Meanwhile, if $K_{1}<1$, the PT route is working inefficiently. In this case, the capacities of the vehicles on the public transport route should be reviewed and smaller capacity vehicles should do the service of this route. If $K_{1}>7 \mathrm{PT}$ then vehicles operating on this route are overcrowded and passengers feel discomfort. This could be one of the factors behind the decrease in public transport demand.

The higher number of passengers per $1 \mathrm{~km}$ is giving more profitable and efficient route. At the same time, public transport vehicles on the routes are not empty, thus reducing empty mileage, which results in losses. 
If $K_{3}<0.78$, the public transport route is unevenly loaded and vehicles are driven empty or undefiled over a certain section. If $K_{3}>1.0$, then the PT route is overfilled with passengers throughout the route, i.e. vehicles carry more passengers than they are intended to. This also reduces passenger comfort.

The cost of travel on public transport routes is particularly important for PT companies. Although the losses incurred by PT routes are covered by municipalities, there are requirements for public transport to be as cost-effective and profitable as possible. Also in pursuit of these goals, the cost to passengers is falling.

The main solutions for the solving problems when the coefficient is falling out of the set ratio are shown in Table 2.

Table 2. Solutions for the solving problems when the coefficient is falling out of the set ratio

\begin{tabular}{|c|c|c|c|}
\hline No. & Criteria & Problem & Possible solutions \\
\hline \multirow[t]{2}{*}{$K_{1}$} & \multirow[t]{2}{*}{ Criteria for transport work } & $1 \mathrm{pass} / \mathrm{m}^{2}>K_{1}$ & $\begin{array}{l}\text { Shorten the route itself by eliminating empty sections of the } \\
\text { route } \\
\text { Serve the route by lower capacity vehicles } \\
\text { Change PT service by booked in advance shuttle service }\end{array}$ \\
\hline & & $K_{1}>7$ pass $/ \mathrm{m}^{2}$ & $\begin{array}{l}\text { Serve the route by higher capacity vehicles } \\
\text { Serve the route with bigger frequency }\end{array}$ \\
\hline$K_{2}$ & Route utility criteria & $K_{2}>5.0$ & $\begin{array}{l}\text { Shorten the route itself by eliminating empty sections of the } \\
\text { route } \\
\text { Change the route to include stops that are more demanding }\end{array}$ \\
\hline \multirow[b]{2}{*}{$K_{3}$} & \multirow[b]{2}{*}{ Vehicle fill unevenness ratio } & $0.8>K_{3}$ & Change the route to include stops that are more demanding \\
\hline & & $K_{3}>1.0$ & $\begin{array}{l}\text { Serve the route by higher capacity vehicles } \\
\text { Serve the route with bigger frequency }\end{array}$ \\
\hline$K_{4}$ & The fare rate & $K_{4}<-0.5$ & $\begin{array}{l}\text { Adapt vehicles to the needs of passenger flows } \\
\text { Shorten or extend public transport routes } \\
\text { Improve service quality }\end{array}$ \\
\hline
\end{tabular}

Citizens are moving from one part of the city to the other, that shows that is necessary to have tool helping to decide how and when to change public transport route. Currently, public transport operators mainly switch routes in response to requests from residents or from businesses. However, this tool (Table 2) would help the public transport operator to respond more quickly to the demographic or other changes in the city and adopt the public transport route network and service without losing money or passengers.

\section{Conclusions}

The following indicators, which influence the efficiency of public transport, are mentioned in the Lithuanian and foreign literature analysing the quality of public transport service: number of trips on the route, relative number of passengers on the route, criteria for transport work, route utility criterion, route Loss Criterion, vehicle fill unevenness factor and fare factor. After reviewing all criteria's the number of journeys on a route, the relative number of passengers on the route, and the route loss criteria were rejected because they are included in the left criteria's expressions.

For a correct and accurate evaluation of PT routes it is necessary to carry out a qualitative study of passenger flows and to evaluate the routes themselves not only on working days but also on weekends. If the indicators are above or below the set coefficients, the public transport routes are inefficient, unprofitable or uncomfortable. In this case, it is suggested to optimize the routes using the available resources and the proposed measures. It also provides tools to optimize and improve the efficiency of public transport routes: adapt vehicles to the needs of passenger flows, shorten or extend public transport routes, and improve service quality.

\section{Author contributions}

Rasa Ušpalytè-Vitkūnienè was responsible for the design and development of the data collection and analysis from Vilnius City and for data interpretation. Justina Kolodinskaja was responsible for literature analysis.

\section{Disclosure statement}

Authors have no any competing financial, professional, or personal interests from other parties. 


\section{References}

Abenoza, R. F., Cats, O., \& Susilo, Y. O. (2017). Travel satisfaction with public transport: Determinants, user classes, regional disparities and their evolution. Transportation Research Part A: Policy and Practice, 95, 64-84. https://doi.org/10.1016/j.tra.2016.11.011

Arampatzis, G., Kiranoudis, C. T., Scaloubacas, P., \& Assimacopoulos, D. (2004). A GIS-based decision support system for planning urban transportation policies. European Journal of Operational Research, 152(2), 465-475. https://doi.org/10.1016/S0377-2217(03)00037-7

Beirão, G., \& Cabral, J. A. S. (2007). Understanding attitudes towards public transport and private car: A qualitative study. Transport Policy, 14(6), 478-489. https://doi.org/10.1016/j.tranpol.2007.04.009

Bozyiğit, A., Alankuş, G., \& Nasiboğlu, E. (2017, October). Public transport route planning: modified dijkstra's algorithm. In 2017 International Conference on Computer Science and Engineering (UBMK) (pp. 502-505). IEEE. https://doi.org/10.1109/UBMK.2017.8093444

Cats, O., \& Jenelius, E. (2015). Planning for the unexpected: the value of reserve capacity for public transport network robustness. Transportation Research Part A: Policy and Practice, 81, 47-61. https://doi.org/10.1016/j.tra.2015.02.013

Cats, O., Susilo, Y. O., \& Reimal, T. (2017). The prospects of fare-free public transport: evidence from Tallinn. Transportation, 44(5), 1083-1104. https://doi.org/10.1007/s11116-016-9695-5

D’Acierno, L., Gallo, M., Biggiero, L., \& Montella, B. (2014). Replanning public transport services in the case of budget reductions. WIT transaction on the Built Environment, 138, 77-88. https://doi.org/10.2495/UT140071

European Commission. Directorate-General for Energy and Transport. (2007). Towards a new culture for urban mobility. Office for Official Publications of the European Communities.

European Union. (2001). White paper-European transport policy for 2010: time to decide. https://edz.bib.uni-mannheim.de/wwwedz/doku/adr/2001/cdr54-2001_fin_ac_en.pdf

Mees, P., \& Dodson, J. (2011). Public transport network planning in Australia: Assessing current practice in Australia's five largest cities (Research paper No. 34). Griffith University.

Mulley, C., \& Nelson, J. D. (2009). Flexible transport services: A new market opportunity for public transport. Research in Transportation Economics, 25(1), 39-45. https://doi.org/10.1016/j.retrec.2009.08.008

Shang, S., Guo, D., Liu, J., \& Liu, K. (2014, July). Human mobility prediction and unobstructed route planning in public tran sport networks. In 2014 IEEE 15 th International Conference on Mobile Data Management (Vol. 2, pp. 43-48). IEEE. https://doi.org/10.1109/MDM.2014.66

Skietrys, E., Raipa, A., \& Smalskys, V. (2008). Viešojo transporto paslaugų efektyvaus valdymo prielaidos. Viešoji politika ir administravimas, 24, 31-38. https://www.mruni.eu/upload/iblock/77a/3_e.skietrys\%20ir\%20kt..pdf

Stone, J., \& Mees, P. (2010). Planning public transport networks in the post-petroleum era. Australian Planner, 47(4), $263-271$. https://doi.org/10.1080/07293682.2010.526550

Turas, V. (2012). Viešojo transporto plètros galimybiu tyrimas Lietuvoje, taikant intelektines transporto sistemas (baigiamasis magistro darbas). Vilniaus Gedimino technikos universitetas.

Van Lierop, D., Badami, M. G., \& El-Geneidy, A. M. (2018). What influences satisfaction and loyalty in public transport? A review of the literature. Transport Reviews, 38(1), 52-72. https://doi.org/10.1080/01441647.2017.1298683 